\title{
A SOCIAL LEARNING THEORY MODEL FOR UNDERSTANDING TEAM-BASED PROFESSIONAL COMMUNICATION LEARNING FOR COMPUTER SCIENCE STUDENTS
}

\author{
C. A. Kalil* \\ email: Claudia.Kalil@uct.ac.za / https://orcid.org/0000-0002-9733-9304
}

\author{
T. Grant ${ }^{*}$ \\ email: Terri.Grant@uct.ac.za \\ *Professional Communication Unit \\ University of Cape Town \\ Cape Town, South Africa
}

\section{ABSTRACT}

The study interrogates an annual course with undergraduate computer science students that took place against the background of national student protests at universities across South Africa to effect equitable access to higher education. As it involved blended approaches and a higher degree of out-of-class digital delivery, it showed that creative pedagogies are possible online and appeal to technologically savvy students, for whom the course was designed in the first place. It uses reflections by these students of their experience of collaborative work on a Scenario Pedagogy (SP) course, as well as the results of a survey of student collaborative practices in a digital space as a window into their learning trajectories. The study demonstrates and offers an understanding of how SP can contribute to developing computer science students as communicators in their discipline at university and future workplaces. It explores the usefulness of Communities of Practice (COP) and Knowledgeability across Landscapes of Practice (KLP) theory as an analytical toolset as well as a descriptive language for investigating and explaining learning events. The changing and changed landscape of higher education and the world of work present new challenges and opportunities, particularly in curriculum development and delivery. Utilising real-world "authentic" pedagogies and social learning theory provides appropriate tools for meeting these challenges. Exploring reflective practices and their contribution to the emerging of transformed practices and identities in the South African higher education sector would be a fruitful avenue of future research.

Keywords: Scenario Pedagogy, Social Learning, Communities of Practice, Knowledgeability across Landscapes of Practice

\section{INTRODUCTION}

“... from my theory's perspective, education institutions are a very peculiar way to structure learning - focussing on the technical dimensions of learning divorced from practice and identity. 
A lot of it ends up being about compliant alignment with curricular demands, with few resources and opportunities for imagination and personal engagement. In fact, its disembodied claim to knowledge is so peculiar that it is no surprise it marginalises many people." (Ettienne WengerTrayner in Farnsworth, Kleanthous, and Wenger-Trayner 2016, 155).

Higher education in a post-apartheid South Africa has been in a state of flux, as institutions have grappled with the challenges of transforming themselves to meet the changing needs of a developing democracy in a globalised economy. The 2015-2017 protests at institutions of higher education across South Africa sent seismic shockwaves through the country. At the epicentre of this quake was a series of student demands around the decolonisation of the education system as well as greater racial and gender equality (Langa 2017). Protests were often violent and disrupted the normal functioning of universities. Universities responded by committing to provide more support to students, transform curricula as well as address more specific institution-based demands put forward by students on each campus. As campuses closed for long periods, innovative online support systems that continued to encourage interpersonal engagement and collaboration were crucial.

Elsewhere, Drenan (2017) has highlighted the challenges of academic and linguistic literacy that many students must overcome in order to successfully complete their studies and showcased the kind of support an institution of higher learning provides to combat such challenges. This article investigates the application of SP and Social Learning theory to collaborative learning in a professional communication course. We explore innovative ways to structure curriculum content and delivery using frameworks that are socially responsive, as alluded to by Wenger in the opening quotation above.

\section{Background}

Developing students to be confident communicators in professional settings raises two important considerations. The first concerns the adequacy of current university curricula to meet the demands of the $21^{\text {st }}$ century workplace. In a study of industry requirements for systems analysts, Karanja et al. (2016) show that, employers prefer entry-level systems analysts who display significant non-technical and people skills. Litchfield, Frawley and Nettleton (2010, 519) point out that, “... the traditional focus of the university curriculum is the professional and disciplinary body-of-knowledge and understandings. This focus is no longer sufficient to meet the various stakeholder needs for graduates with contemporary workplace professional attributes, understandings and skills." The second consideration is that many recent graduates lack professional writing skills, even though this is critical to professional success (Smart, Hicks and Melton 2013). It is apparent that recent graduates in technical fields are under-prepared for 
the communication demands of the workplace.

The academy has responded to these shifting trends in the workplace through innovative curriculum content and delivery. Bremner et al. $(2014,150)$ claim that "the importance and prevalence of collaborative writing as a feature of workplace activity are now for the most part taken as given”. Gruba and Søndergaard $(2001,203)$ argue for joint practice. They maintain that students learn best when they "face complex, real world problems in which there are no clear answers. Faced with a sizable common goal, students work collaboratively towards outcomes and maintain ownership over key decisions." Grant $(2012,11)$, in rationalising the design of Scenario Pedagogy (SP), the vehicle on which this article is based, argues for a collaborative and coherent multimodal approach to pedagogy, which is characterised by a range of verbal, non-verbal and visual communicative and representational resources, not language alone. Such an approach requires interchangeable and negotiated roles of teacher and learner and a "willingness of participants to negotiate status differences and assume or relinquish authority where relevant and appropriate; and approaches to pedagogy and course design which reflect sustainability and encourage students to adopt transformative practices for a rapidly changing and challenged world". Kress (2010) notes that meaning arises in social environments and through social interactions. Consequently, communication is achieved in a variety of modes such as written, spoken and visual as well as ensembles of gaze, stance and gesture.

Responding to these trends, we have been using SP to teach professional communication to science and commerce students at our university. All assignments and activities are linked to scenarios such as institutional environmental sustainability, or developing, maintaining and harnessing Information and Communication Technologies (ICTS) to support blended learning at the university. While getting input on communication practices such as report writing or presentation skills from professional communication specialists, student teams draw on their own expertise in, for example, business or computer science to investigate a dimension of the chosen scenario. Team-based activities create opportunities to harness the dialogical synergies of collaborative learning. Use of traditional and digital literacies, and multimodal artefacts and processes, facilitates embodied experience of professional and academic multiliteracies for communication practice. Archer and Newfield (2014) have pointed out that employing multimodal pedagogies involves the recognition of resources that students bring with them particularly multilingual, experiential and embodied resources that are often not valued in higher education. We argue that when professional communication lecturers facilitate collaboration around the scenario (with faculty, management experts, staff and students) and draw on student's expert subject knowledge, they engender a flat power dynamic, effect ownership of learning and enable the transformation of identities. As a context-sensitive, real- 
time approach to teaching professional communication, we argue that SP represents a robust model for teaching professional communication (Grant 1999; Grant and Kalil 2011; Grant 2012; Grant and Archer 2019).

While we recognise that the SP implementations are responsive to social characteristics of the learning environment, we had not directly investigated how social features of the pedagogy might create the conditions conducive to teaching and learning of integrated multimodal communication practice. In using SP, we noticed the emphasis students placed in course evaluations on the benefits and enjoyment of embodied interpersonal communication and teamwork. We also saw that methods of accomplishing academic work were changing rapidly in response to a range of pressures. These include widespread ownership of computer devices, cheaper and more widespread access to the internet and the proliferation of dissemination and collaboration ICTs. Socially, political conscientisation and the consequent heightened political disruption and tensions on campus were driving reliance on digital technologies for blended learning. ${ }^{1}$

\section{Social learning theory}

To address the gap in understanding the social learning affordances of SP, we interrogated an annual course with undergraduate computer science students by analysing student reflections and surveying student collaborative practices in teams in the digital space. Finding a theoretical framework to explore the social-educational context became essential and social learning theory provided a good fit. Wenger-Trayner (Farnsworth et al. 2016, 141) defines social learning theory as "a set of technical terms that together form a coherent perspective on the social dimension of the human condition ... validated through its usefulness for telling meaningful stories about the human condition”. Communities of Practice (COP) (Wenger 1998) theory and Knowledgeability across Landscapes of Practice (KLP) theory, (Wenger-Trayner, FentonO'Creevy, and Wenger-Trayner 2015), an evolvement of COP, both focus on the relation between the person and the social world as they constitute each other.

\section{Aims and relevance}

We therefore use the theoretical tools that COP and KLP offer to explain or predict how SP's social attributes provide a coordinated strategy, or can be used as one, to create conditions for learning contemporary professional communication practice, and be responsive to challenging conditions in the university. We are also interested in how useful the theory would be for understanding learning interventions. The study aims are therefore relevant to educators for two reasons: 
- Firstly, the study demonstrates and clarifies how a specific pedagogy, SP, can contribute to developing computer science/technical students as communicators in their disciplines, at university and future workplaces.

- Secondly, the study explores the usefulness of COP/KLP theory as an analytical toolset as well as a descriptive language for investigating and explaining learning events (Omidvar and Kislov 2014).

\section{Plan of development}

The body of this article is structured in four major sections. Section two sets out the method of investigation. Section three expands on the evolution and key constructs of COP and the shift to its newer iteration KLP. As the newer iterations have key constructs that are new to COP theory, we refer to this as a discrete theory, KLP. These constructs are relevant for the analysis of findings on SP. The analysis traces the collaborative journey of students across the digital and campus landscapes embedded in the scenario they investigate. Section four describes two iterations of the annual course with computer science undergraduate students. Finally, in Section five, themes in the reflections are analysed using key constructs of theory. Conclusions are drawn about learning in SP as well as the value of COP/KLP theory for scrutinising and understanding the value of an educational intervention.

\section{METHODOLOGY}

Using the premise that learning is socially situated, the study primarily "seeks explanation within the realm of individual consciousness and subjectivity, within the frame of reference of the participant as opposed to the observer of action" (Burrell and Morgan 1979, 28). With a focus on understanding the world at the level of subjective experience, this study therefore employs an interpretivist/social constructivist paradigm.

The study uses computer science students' reflections on their experience of collaborative work on the SP course. We re-coded these based on our own extensive work as designers and facilitators of SP courses as well as constructs from the literature on social learning and multimodality. The role of reflection in learning is widely recognised. Tracing the history of management as a discipline, Lawrence $(2013,195)$ points out how personal reflective practice in management education is "concerned with leadership theory and practice, and therefore, with efficiency, decision-making and goal setting”. Selber $(2004,147)$ writes of students as needing to be reflective producers of technology who understand texts as inherently social artefacts involving larger structures and forces, who through various deliberative activities "subject their actions and practices to critical assessment" to improve their own performance. Following 
Habermas (1984), Mezirow $(1990,11)$ posits that the purpose of reflection is to validate what is known. If reflecting involves critically viewing distorted epistemic, sociocultural or psychic presuppositions, it "can lead to transformative learning" [author's italics]. Using the voices of students as "heard" in reflections and in the feedback to the survey as a window into their learning trajectories is supported by research in which students are increasingly viewed as coproducers of knowledge. Cope and Kalantzis $(1993,6)$ have termed this "authentic pedagogy".

\section{ANALYTICAL FRAMEWORK}

Social learning theorists study learning in a social setting by observing the practices that evolve through processes of trial and error. Hence, they extract information about how participating in learning interactions produces insights and resources that change and transform practices to improve outcomes and potentially transform not only the participants, but also their environment (Wenger-Trayner et al. 2015). In this environment learning as identity formation takes place on two levels:

- Firstly, it involves expressing one's competence and knowledgeability in individual and overlapping communities to which one belongs and the extent to which others in the community affirm (or do not affirm) such competence; it is about how one negotiates membership in a landscape of practice.

- Secondly, it comprises the extent to which one's participation in a community of practice enters one's own identity as a person in a more general way.

Learning as identity formation is achieved through a complex set of creative tensions, depicted in Figure 1, through which learning outcomes/knowledgeability are negotiated: that is, through meaning, practice, expertise, and identity and leadership.

In presenting our findings in section five of this article, we deviate slightly from the model in substituting collaboration for expertise.

From a KLP perspective, learning outcomes in the areas depicted in Figure 1 are achieved through identification and dis-identification processes. This involves modes of participation where a mode encapsulates how an individual orientates herself in the landscape of practice (Wenger-Trayner et al. 2015). The identification processes involve three modes: engagement, imagination and alignment. The authors note, however, that as power dynamics exist between communities, yet each has its own internal logic, one practice does not subsume another. This makes the landscape "flat" yet a place of contestation. Thus, through a combination of the three modes of practice, knowledgeability is developed in the crucible of experience. Although 
modes of identification are distinct, their real power and effectiveness derive in combination.

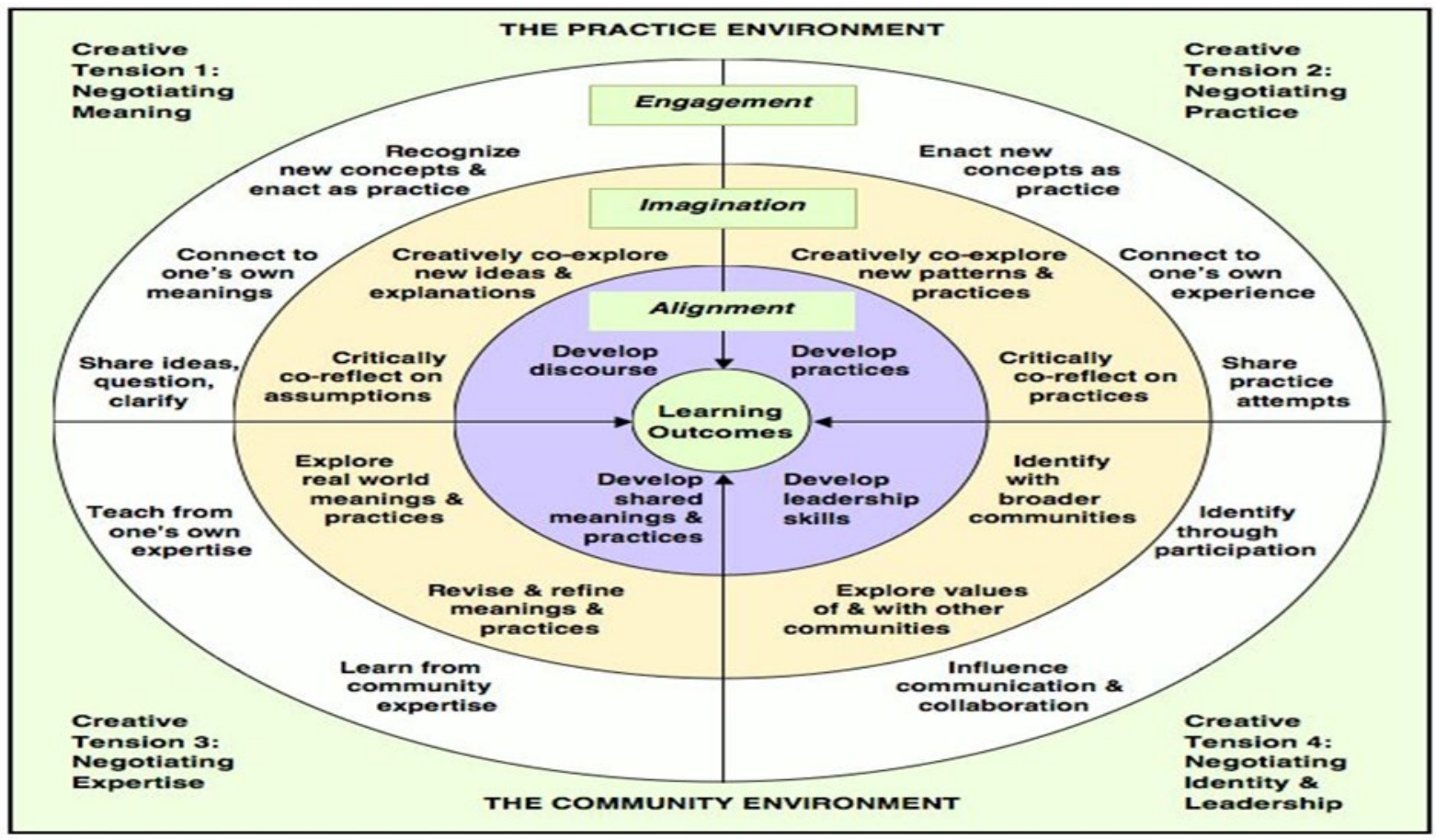

Figure 1: Sourced from Communities of Practice Learning Model by Joyce Yukawa (2012)

We expand the explanation of these key modes of identity creation to clarify how they represent the creative tensions in a practice and community environment:

- Engagement is participation in practices and communities in a landscape to which members are accountable (i.e., recognised as competent and in good standing), and in which they can express their competence. A typical example would be membership of and participation in a professional body that enables a practitioner to practice their profession.

- Imagination involves the ability to conceive what an experience may be like, or imagine a future, or what someone else experienced, or a history, or indeed see oneself in another setting or time. Typically, it involves the construction of mental schemata of a domain of theory and practice, and the possibilities that they offer.

- While engagement in practice, most immediately, is essential, feeling alignment with the practices and a sense of belonging to the community of practice are also critical. This is not merely a process of compliance with community structures, but a reciprocal effort to up-hold and co-ordinate such structures (Wenger-Trayner, Fenton-O'Creevy and WengerTrayner 2015). 


\section{SCENARIO PEDAGOGY}

Two iterations of SP in practice illustrate the implementation of SP. In the first iteration, computer science students were divided into two classes with twelve and fifteen teams of four members within each class respectively. The scenario in focus was information and communication technologies (ICTs) in education at the university. Prior to the start, two scenario specialists from the Information and Communication Technology Services department (ICTS) and the Centre for Innovative Learning and Teaching (CILT) devised 15 sub-scenarios relating to promoting learning using technology at the university. Examples of sub-scenarios included investigations into the university mobile app, biometric identification in examinations, gamification of learning, using tablets for learning and teaching, learning and teaching in the Cloud, classroom renovation and equipment, development of open content, and the establishment of MOOCS at the university.

In contrast, in the second iteration, the umbrella scenario related to the nation-wide sociopolitical events connected with establishing free higher education, the "\#FeesMustFall" movement. Disruptions of campus and residence life and at times violent protest action had caused campus closure for months. The events precipitated cancellation of lectures and transfer into distance learning modes and online exams. Teams generated their own sub-scenarios, therefore requiring no pre-course planning with scenario specialists for the facilitators. Each team investigated an online method adopted for teaching and learning during the "closed campus" period, staff and student perceptions of the method selected, and alternative approaches to using this method at local and international institutions. Teams then drew conclusions on and devised recommendations for improving the method for future programmes at the university to ensure ongoing quality of teaching and learning.

These are some of the student report titles: The Flipped Classroom Model and UCT in context of its access constraints; Substituting Course Work with MOOC-like Content in a Moment of Crisis; The Use of Gamification as a Blended Learning method - a case study; The Effectiveness of Vula (the learning management system) with a Focus on Lecture Recordings; and The Accessibility to Broadband and Data in a Blended Learning Environment. ${ }^{2}$

Against this background, the next section presents the findings of the study and a discussion from the perspective of social learning theory.

\section{FINDINGS AND DISCUSSION}

"Engagement without imagination or alignment is at risk of local blindness - this is the way we do things here because we have always done them that way." (Wenger-Trayner et al. 2015, 22). 
"The landscape, however, is well colonized and some hills are well guarded. Some communities may welcome us, while others may reject us. The experience can be one of painful marginalization or merely the chance to move on." (Wenger-Trayner et al. 2015, 20)

The quotations from Wenger-Trayner above, highlight some of the challenges involved in navigating landscapes of practice. A social body of knowledge comprises more than a community but different dynamic communities involved in dimensions of an occupation "with their own histories, domains, and regimes of competence" (Wenger-Trayner et al. 2015, 15), that evolve, break up, reject or engage members or practices. In this section, we discuss the creative tensions in the landscape of practice that the course represented vis-a-vis students' reflections on their learning. We use the analytical framework derived from Yukawa (2012) and Wenger-Trayner et al. (2015), COP/KLP described in section 3 above. We attempt to understand the role of encounters with people, objects and processes on SP, in building knowledgeability and transforming identities in the intersecting communities that teams embedded in the umbrella scenario represented.

\section{Negotiating meaning}

The journey of each participant on the course was characterised by engagement with new concepts, enacting these as practice and personally making sense of it all. Thus, whether interviewing the director of the Computer Systems Division of ICTS at the university, polling classmates' opinions on lecture recordings, or conducting an online investigation of blended learning at a university in the United Kingdom, students negotiated meaning and developed the discourse that aligned them to dimensions of university life and issues in higher education encapsulated by the scenario. Such sense making, where one's own meanings connect with what others share, is transformative. According to Kress $(2010,74)$ "learning is the result of a semiotic/conceptual/meaning-making engagement with an aspect of the world; [and] as a result the learner's semiotic/conceptual resources for making meaning and, therefore, for acting in the world, are changed - they are augmented".

Student reflections index the identification processes involved in the creative tensions that arose when negotiating meaning. They reveal what students recognised as valuable in building knowledgeability that aligns with their current academic and future professional lives:

"The [...] discussion allowed us to gain a broad view of the subject areas."

"[It] allows students to learn writing principles while focusing on their area of expertise."

"teaches skills we wouldn't learn in other courses."

"teaches people how to pass ideas and discoveries found onto a language that can be understood 
internationally."

"[it will be] helpful in terms of writing [a] thesis and doing research"

"may seem a burden, [but is] actually ... beneficial ... essential for our future endeavours."

"[Collaboration is] a feature of work after graduation"

"undoubtedly a valuable skill; after all, in the professional world, writing is often a collaborative effort"

Comments such as these point to an understanding of how the practices developed during the course positioned students as future professional communicators.

Engagement generating multimodal artefacts provided opportunities for collaboration and innovation, and embedded students' competencies and identities more intensively in the computer science landscape of practice. As such, student practices were aligned with the knowledgeability of the broader regime of competence in the scenario.

\section{Negotiating practice}

Communicating professionally, whether in the academic space or future workplace, involves standard practices as well as creative ways of co-exploring and co-reflecting on new ways of being and doing. Students encountered or discovered new concepts but also enacted these as practice, alone or shared, and connected concepts to their own meaning/experience. Thus, the multiple macro- and micro-activities on the journey through the landscape of practice that the scenario represents served as encounters to embed concepts and practices into the identities of those engaged.

Typical encounters included using research and business practices, from exercising the conventions of the report genre, to running surveys of student opinion, to collaborating online to create documents, or delivering Power Point presentations, to writing informatively to convey the "objectivity" of findings, or inferentially using modals and hedges (the scientific method). Composition of messages required students to:

- $\quad$ grapple with affordances of words to express precise meanings;

- $\quad$ gauge register as a function of purpose and audience;

- $\quad$ operationalise communication principles of unity, coherence and emphasis;

- $\quad$ reason with different logics, and

- $\quad$ exercise explanatory and predictive rationales.

These stimulated processes of divergent and convergent thinking created the tensions through 
which to develop professional communication practice. Students noted that these encounters led to "refined thinking" and "streamlined arguments".

A range of activities, such as presenting drafts in various sites of display, moving from page to screen, poster or document to PowerPoint presentation, receiving feedback, refining ideas, and redesigning in a different mode and site of display, stimulated recursive involvement of joint processes: problem-solving, negotiating, decision-making, planning, and innovating (Grant 2012; Grant and Archer 2019). The iterative processes of drafting and re-drafting reports based on feedback from peers and self-examination meant questioning previously accepted assumptions and as such catalysed a cycle of composition, reflection and revision. A large majority of respondents to the end of course survey (72\%) agreed that this cycle of drafting and redrafting was useful in shaping the writing process and provided for a smooth transition between starting, planning and preventing writer's block in the composition of their academic work:

"From this course $\mathrm{i}$ have some gained knowledge on how to write in a professional way and $\mathrm{i}$ think that what $\mathrm{i}$ have experienced is going to be helpful to me in the future on doing other work" (sic).

"The planning process was really helpful."

The need to re-examine concepts and premises in the re-working of reports represented a realignment of beliefs and practices. The performative aspects of the course such as presenting mind maps and using PowerPoint presentations, while serving as exploration of real-world meanings, also contributed to building competence and confidence as professional communicators accountable to and aligned with the demands of the profession and workplace.

In grappling with designing their investigations, administering research instruments and planning their writing students worked with various objects and people and an array of technologies: computers, mobile devices, databases, libraries and the internet. They used ICTs widely in out-of-classroom production of draft products and for presentation of these, whether individually or collaboratively. They used Word for their final assignments and applications such as Google docs, Skype, WhatsApp, Overleaf and Vula (learning management system) for virtual collaboration in writing and publishing the final assignment/s. They used dissemination ICTs such as PowerPoint and Prezi in formal presentations of draft products such as mind map posters and progress reports. Students had to master ICTs used on the course in ways they would not necessarily have done in their core discipline activities. Thus, through enacting new concepts as practice and doing this in a shared way in teams and across the scenario, students could build on their own experience, ultimately stimulating alignment with and identity- 
creation within the practice and community environments of the socio-educational scenario.

Digital and computer practices are important in defining competence in contemporary professional practice domains. Selber (2004) maintains that computer literacy is a domain of writing and communication. Using ICTs in the social, semiotic, temporal and spatial locations (Roberts 2006) on the course therefore meant developing expanded digital production and virtual collaboration literacies. Engagement with technology in virtual team environments also enabled students to align with and imagine themselves in professional communication spaces and practices. Practitioners primarily use dissemination ICTs in one-way communications for sharing or distributing scientific findings within a discipline, the broader scientific community and other social groupings. According to Lamb and Davidson (2005), they "enable identity avowals by scientists as well as identity ascriptions by the audience, and are resources for identity construction, deconstruction and reconstruction". As such, ICTs as tools in team processes served as boundary objects in crossing communities in the landscape of practice. Whether using a physical hardcopy poster or digital version of a mind map, for instance, getting the team-based message across was manifestly possible. Consequently, manipulation of boundary objects served as boundary encounters for stimulating professional learning and belonging.

\section{Negotiating collaboration}

Course participants undertook a variety of cooperative activities, such as off campus meetings (face-to-face and virtual), joint writing activities and production and presentation of visual artefacts that served to immerse them in collaborative practice. Writing in teams where the project was big enough that work had to be shared and required interdependence of a small group to achieve their goals, stimulated the intense demands of teamwork (Katzenbach and Smith 1993). When students collaborated in teams, they were learning from others as well as sharing their own expertise. Reflections indicated the views of students on the creative tensions that arose in teams:

"[It] is more effective in learning than [the] traditional mode of lecture teaching" "encourages critically evaluating your ideas"

"challenges you to think as part of a group to bring one idea together."

Many focused on the reduced effort and pressure for individuals that collaborative negotiation of expertise expedited: "You don't have to struggle on your own".

Pressures deriving from cooperative work represented other tensions in negotiating 
expertise. For instance, multiple deadlines with quick turn-around times for presenting draft assignments meant teams had time and logistical pressures in completing work. Asynchronous labour divisions added a dimension to organisation. Thus, not all project activities took place simultaneously, required team members to work closely during each step of the project, or be in the same (real or virtual) space. Teams also distributed their effort by each writing a different section of the assignment. For example, only two of four members undertook an interview, only one member generated illustrations or collated work or edited the final document. Delegation allowed students to play to their strengths.

Numerous comments on time-management and managing group logistics signalled the steepness of the learning curve in this respect: "The organization of weekly meetings and their attendance taught me the importance of putting other things aside to focus on the task at hand."

At times students were not sufficiently organised and had to suffer concomitant disappointment and loss of marks, as the following statement shows:

"Although the planning was very beneficial the actual procedure of writing the paper was quite tricky. With many colliding deadlines and management issues within our team ... we had to unfortunately finalise the writing of our paper the day after submission was due."

Students grappled with issues of accountability when team members were not answerable. Periodically, commitment across the team was uneven as the following reflections show:

"[Members] didn't pull their weight ... forcing the rest ... to do more than their share of the work." "Members didn't always volunteer when work needed to be done."

"A lot of time was wasted on waiting for responses and agreement from group members."

Reflections on dealing with less cooperative team members signal students obtaining experience and related learning outcomes through managing testing workplace team communication challenges, such as negotiating with difficult people, managing conflict, and accommodating personality, styles and attitude differences.

A further student comment revealed a different aspect of negotiating expertise, a struggle with separating social and work aspects: "When we were together, we were distracted by talking about other (non-work related) things."

Skills such as praise, feedback or expressing support represented an additional area of developing shared meanings and practices involved in maintaining effective teams: "Although motivation was a bit lacking at times, we ... pushed each other along when necessary."

Student practices and perceptions on collaborating online and face-to-face index their 
influence on developing professional literacies and identities. Notwithstanding that a certain amount of preparation had to be done individually, 42 per cent of students surveyed spent over 40 per cent of their time working online as a team $(19 \%$ as $40-60 \% ; 17 \%$ as $60-80 \% ; 6 \%$ as 80-100\%). In addition, 39 per cent of students spent over 40 per cent of their time working face to face: $(17 \%$ as $40-60 \% ; 17 \%$ as $60-80 \% ; 5 \%$ as $80-100 \%)$. Reflecting on their communication and work practices 58 per cent of students agreed that working online was as productive as working face-to-face. Significantly, 63 per cent felt that working collaboratively was more rewarding than working alone, however.

In their review of case studies on virtual teams Chatfield et al. (2013) identified key organisational challenges in the virtual environment as "effective communication, knowledge sharing, trust, and interpersonal skills". Walther (1996) and Han and Beyerlein $(2014,16)$ found evidence that "virtual interactions can lead to development of more intense interpersonal relationships than face-to-face interactions, because virtual interactions allow individuals more control over how they present themselves". When students worked as virtual teams, they could negotiate these tensions through contrasting experiences of face-to-face versus online (synchronous and asynchronous) work, and as such become co-constructors of knowledge involved in co-creation of learning.

\section{Negotiating identity and leadership}

Reflections on participation in SP reflected the capacity for identity work and leadership development that the organisational framework of SP constructed. Active participation in teams, reciprocally influencing others and feeling the influence of others, signalled emergent identity and leadership practices. With collaboration and cooperation features foregrounded, students' identities, abilities or social connections were not foregrounded or denigrated (Gee 2003). This situation therefore has implications for further embedding students' competencies and bolstering their identities as professional communicators in the computer science landscape of practice.

Reflections that demonstrate a meta-understanding of intergroup dynamics index this growth: "While I learned a bit about writing, its challenges and obstacles, what I really learnt is that groups are really difficult to organize and motivate. And that knowledge, I believe, is fundamental."

There were insights into how teams can (and cannot) work: "If we all agree on our common objective it is easy to approach your group with ideas freely and creates a[n] understanding environment." There were comments on leadership style in a team: 
"One person took leadership, which was important to give the rest of the team direction, but they didn't do all the work."

"I learned that it is important that someone takes on a leadership role but continues to work as part of the team."

The following student recognised the importance of a relaxed climate for being productive in a team: "A team can laugh and have a joke in-between. [This is still] an effective team when it comes to getting the job done."

The next comment shows the importance of a common understanding for working well collaboratively: "Not having a clear, shared vision for the projected resulted in fragmentation".

A student was also able to compare with previous team experiences and learned from that:

"Comparing this group (we chose our own members) to my CSC Networks group (we were assigned group members), it was much easier and more enjoyable working with people I know. I also found it easier to plan the project and resolve issues with this group."

When students worked in teams, they saw each other in a different light than if they were mere individuals in a class of many, each working alone. Emotional responses towards the experience that had a tone of celebration signal this, as the following statements show:

"It was a great experience. The different minds were fascinating."

"A team of 3 guys and one girl, all of them amazing and very intellectual. I have enjoyed working with those hard working and dedicated people."

"We were very opinionated individuals. Working with them was enlightening and interesting."

"Nice experience working with new different people."

Comments pointed to the synergies that come from working in diverse teams.

"The team were students with varying majors, and varying talents."

"We all came from different countries, races and backgrounds thus we had diversity and did not run out of ideas on what to write."

Some statements signalled how participation exercised empathy and imagination:

"Working with others who have different opinions forces one to analyse and interpret outside of one's reference framework."

"Promotes interaction with people outside of your social circle." 
Combined, the reflections are indicative of processes where students could compare prior mental models of the world and relate these to new models, whether they conflicted with or otherwise related to them (Gee 2003).

Encounters with difference in respect of background, race, ethnicity, personalities, and styles of working created dynamic encounters. Wenger-Trayner et al. $(2015,17)$ explain the tensions that encounters with others in a landscape of practice can induce: "Because of the lack of shared history, boundaries are places of potential misunderstanding and confusion arising from different regimes of competence, commitments, values, repertoires, and perspectives".

Engagement in teams meant exploration of values within teams and across the scenario. These reflections show the impact of engagement on their own and others' attitudes and values. Students recognised the adjustments required because of differences on various levels:

"I think it depends on your team. Ultimately, it's the responsibility of every member and 3rd year CS (Computer Science) is a filter for good programming, not good writing, so you can land up with incompetent partners."

"A lot had to be put aside just to ensure that things were done for all of us to be happy."

Encounters in traversing the landscape were thus not always favourable: Styles of and preferences for working, the difficulties this brings up, and how to manage these emerged:

“One member wasn't working to the deadlines we set, and the other student work was just not up to scratch. It taught me to manage my expectations of others in a group, make sure everyone knows what direction they need to take, and not assume everyone knows what direction the project is going."

When students worked in teams it produced issues such as not getting along with team members, or dis-location from their comfort zones, as these comments demonstrate:

"Group members [were] slack".

"I found it frustrating as my team did not care as much as I did about getting the task right."

There was the view that it was:

"not an accurate reflection of each group member's abilities".

"some groups may be dominated by an individual's interests meaning the other group members are less interested".

Grappling with both the rough and the smooth inherent in traversing landscapes of practice is evident in the reflections. 
In summary, the practice and community environments formed the backdrop for processes of engagement, alignment and imagination where negotiating meaning evolved into negotiating practice, expertise, identity and leadership. Ultimately, they echo the seamless integration of the different quadrants in the learning model. What emerges theoretically therefore is a continuous loop and dynamic interplay between the four dimensions in the model.

In practical terms, the reflections convey the extent to which the course fostered the negotiation of boundaries, transformative learning experiences, co-exploration of new concepts and critical reflection and co-reflection on practice. Therefore, those who completed the SP course developed, "adaptive flexibility in learning style ... predictive of highly integrated and complex levels of adult development" (Kolb, Boyatzis, and Mainemelis 1999).

\section{CONCLUSION}

In the aftermath of the \#FeesMustFall movement, the higher education landscape in South Africa realised the importance of engaging with the challenges that gave rise to the student protests of 2015 to 2017 . These challenges continue to speak to several burning issues around equitable access to higher education, which fall outside the ambit of the present study. Instead, our focus has been on employing collaborative pedagogies and social learning theory to evaluate current pedagogical and curriculum practices, with a view to deriving key lessons that will aid in shaping innovation and transformation for educators and students and institutions of higher learning. Our key findings from the present study are:

- The changing and changed landscape of higher education and the world of work present new challenges and opportunities, particularly in curriculum development and delivery. Educators can utilise real-world scenarios, "authentic" pedagogies and social learning theory as appropriate tools for meeting these challenges.

- Growing knowledgeability involves a complex nexus of identification, alignment and imagination processes. Hence, professional communication courses benefit greatly from employing pedagogies that provide extensive opportunities for application of modes of engagement, alignment and imagination to foster the development of professional identities and consequently individual, institutional and community transformation.

- Social learning is characterised by ongoing tensions in four key areas: negotiating meaning; negotiating practice; negotiating collaborative experience and negotiating identity and leadership. In the process of negotiating meaning students and faculty members engage with frames of reference from prior experiences as they encounter new 
concepts and experiences. SP affords students and educators the opportunity to question the relevance of concepts they encounter, critique these concepts and evaluate their impact on their practice and emergent professional lives.

- Central to this process is ongoing reflection by all participants, and the emerging of transformed practices and identities - an area that we are keen to explore in future research. Such reflection speaks to the second tension characteristic of social learning: negotiating expertise. At the heart of the social learning landscape lies the process of building relationships through participation. Participation too, is a reciprocal process, a dynamic dance that shapes identity through creatively resolving tensions and challenges encountered in the landscape of learning. These nodes of tension give rise to issues of accountability towards others and expressibility of interest, and the challenges that such imply. We suggest that this too provides fertile ground for future research.

Equally, modes of curriculum delivery, particularly utilising multimodal vehicles as well as exploring the possibilities of a greater shift to online learning and extending the classroom beyond the confines of lecture theatres, provide exciting possibilities to effect greater transformational learning environments. The possibilities that multimodality and porous classroom walls give rise to, reverberate with Achille Mbembe's (2015) argument in his speech Decolonizing Knowledge and the Question of the Archive, that to Africanise is a search for a liberating perspective where we "see ourselves clearly in the relationship to ourselves and to other selves in the universe"; where "other selves" is a term "open-ended enough to include ... all sorts of living species and objects, the biosphere itself'. In the university such selves develop in the crucible of engagement, alignment and imagination as they criss-cross the university landscape of practice, and beyond to professional contexts.

Against this background, we invite readers to respond to issues and concerns raised in this article as well as to the general thrust of the social learning perspective. We view this article as a contribution to shaping a broader debate around creative pedagogies and social learning theory and their role in transforming higher education.

\section{NOTES}

1. Since the Covid-19 pandemic, reliance on digital technologies has taken on a new urgency. The proliferation and increasing sophistication of such technologies has contributed to sustaining educational goals and allowing the academic project to continue.

2. Much of this move to digital teaching and learning has proved invaluable during the pandemic when campuses closed, and distance education became the "new normal". 


\section{REFERENCES}

Archer, A. and D. Newfield. 2014. "Challenges and opportunities of multimodal approaches to education in South Africa." In Multimodal approaches to research and pedagogy: Recognition, resources and access, ed. A. Archer and D. Newfield, 1-18. Oxon and New York: Routledge.

Bremner, S., A. Peirson-Smith, R. Jones, and V. Bhatia. 2014. "Task Design and Interaction in Collaborative Writing: The Students' Story." Business and Professional Communication Quarterly 77(2): 150-168.

Burrell, G. and G. Morgan. 1979. Sociological Paradigms and Organizational Analysis. London: Heinemann.

Chatfield, A., V. N. Shlemoon, W. Redublado, and G. Darbyshire. 2013. "Creating value through virtual teams: A current literature review." Twenty-Fourth Australasian Conference on Information Systems, 1-11. Australia: RMIT University. http://ro.uow.edu.au/cgi/viewcontent.cgi? article $=3346 \&$ context $=$ eispapers.

Cope, B. and M. Kalantzis. (Eds.). 1993. The Powers of Literacy: A Genre Approach to Teaching Writing. London: Falmer Press.

Drenan, L. M. 2017. "Engaging students through writing: A collaborative journey." South African Journal of Higher Education 31(3): 63-81.

Farnsworth, V., I. Kleanthous, and E. Wenger-Trayner. 2016. "Communities of Practice as a Social Theory of Learning: A Conversation with Etienne Wenger." British Journal of Educational Studies 64(2): 139-160.

Gee, J. P. 2003. What video games have to teach us about learning and literacy. New York: Palgrave Macmillan.

Grant, T. and A. Archer. 2019. "Multimodal mapping: Using mind maps to negotiate professional communication practices and identity in higher education." South African Journal of Higher Education 33(1): 74-91. http://dx.doi.org/10.20853/33-1-2758.

Grant, T. and C. Kalil. 2011. "Information systems as a social space: developing academic and social literacies in students." International Journal of Humanities and Social Science 1(9): 29-39.

Grant, T. 1999. "Scenario learning: An outcomes-based approach to enhance students' communication ability." South African Journal of Higher Education 13(3): 36-45.

Grant, T. 2012. "Scenario pedagogy as a negotiated, multimodal approach to developing professional communication practices in higher education." Unpublished doctoral dissertation, University of Cape Town.

Gruba, P. and H. Søndergaard. 2001. "A Constructivist Approach to Communication Skills Instruction in Computer Science." Computer Science Education 11(3): 203-219.

Habermas, J. 1984. The theory of communicative action volume 1: Reason and the rationalization of society. Translated by Thomas Mc Carthy. Boston: Beacon Press.

Han, S. J. and M. Beyerlein. 2014. Managing culturally diverse virtual teams: A systematic literature review. Working Paper. https://www.ufhrd.co.uk/wordpress/wp-content/uploads/2014/11/SooJeoung-Han.pdf.

Karanja, E., D. M. Grant, S. Freeman, and D. Anyiwo. 2016. "Entry level systems analysts: What does the industry want?" Informing Science: The International Journal of an Emerging Transdiscipline 19: $141-160$.

Katzenbach, Jon R. and Douglas Smith. 1993. The Wisdom of Teams: Creating the High-performance Organization. Brighton: Harvard Business Press.

Kolb, D. A., R. E. Boyatzis, and C. Mainemelis. 1999. "Experiential Learning Theory: Previous Research and New Directions." In Perspectives on Cognitive Learning and Thinking Styles, ed. Robert J. Sternberg and Zhang Li-Fang. New Jersey: Lawrence Erlbaum.

Kress, G. R. 2010. Multimodality: A social semiotic approach to contemporary communication. London: Routledge. 
Lamb, R. and E. Davidson. 2005. "Information and Communication Technology Challenges to Professional Identity." The Information Society 21(1): 1-24.

Langa, M. (Ed.). 2017. \#Hashtag!: An analysis of the \#FeesMustFall Movement at South African Universities. Centre for the Study of Violence and Reconciliation. Johannesburg South Africa. http://www.csvr.org.za/publications/latest-publications/2674-hashtag-an-analysis-of-thefeesmustfall-movement-at-south-african-universities.pdf.

Lawrence, H. 2013. "Personal reflective writing: A pedagogical strategy for teaching business students to write." Business Communication Quarterly 76(2): 192-206.

Litchfield, A., J. Frawley, and S. Nettleton. 2010. "Contextualising and integrating into the curriculum the learning and teaching of work-ready professional graduate attributes." Higher Education Research and Development 29(5): 519-534.

Mbembe, A. J. 2015. "Decolonizing knowledge and the question of the archive." Speech delivered at Wits Institute for Social and Economic Research on 22 April 2015. https://wiser.wits.ac.za/ system/files/Achille $\% 20$ Mbembe $\% 20-\% 20$ Decolonizing $\% 20$ Knowledge $\% 20$ and $\% 20$ the $\% 20$ Question\%20of\%20the\%20Archive.pdf.

Mezirow, J. 1990. "Fostering Critical Reflection in Adulthood A Guide to Transformative and Emancipatory Learning 'How Critical Reflection Triggers Transformative Learning'." https://my.liberatedleaders.com.au/wp-content/uploads/2017/02/How-Critical-Reflectiontriggers-Transformative-Learning-Mezirow.pdf.

Omidvar, O. and R. Kislov. 2014. "The Evolution of Communities of Practice Approach: Towards Knowledgeability in a Landscape of Practice - An Interview with Etienne Wenger-Trayner." Journal of Management Inquiry 23(3): 266-275.

Roberts, J. 2006. "Limits to communities of practice.” Journal of Management Studies 43(3): 623-639.

Selber, S. A. 2004. Multiliteracies for a digital age. Carbondale: Southern Illinois University Press.

Smart, K. L., N. Hicks, and J. Melton. 2013. "Using Problem-Based Scenarios to Teach Writing." Business and Professional Communication Quarterly 76(1): 72- 81.

Walther, J. B. 1996. "Computer-Mediated Communication: Impersonal, Interpersonal, and Hyperpersonal Interaction." Communication Research 23(1): 3-43.

Wenger, E. 1998. Communities of practice: Learning, Meaning and Identity. Cambridge: Cambridge University Press.

Wenger-Trayner, E., M. Fenton-O'Creevy, and B. Wenger-Trayner. (Eds.). 2015. Learning in Landscapes of Practice: Boundaries, Identity, and Knowledgeability in Practice-Based Learning. London: Routledge.

Yukawa, J. 2012. “Communities of Practice.” http://www.jyukawa.com/main/cop. 